\title{
LOS LÍMITES DEL TEATRO DE JOSÉ BERGAMÍN Y EL EXILIO COMO CONTRA-TIEMPO*
}

\author{
Max Hidalgo Nácher \\ Universitat de Barcelona - GEXEL/CEFID
}

\begin{abstract}
RESUMEN / ABSTRACT
La posición liminar de José Bergamín en la historia de la literatura española se concreta actualmente en la dificultad de leer sus textos y de integrarlos en una historia a la que, sin embargo, pertenecen. Este artículo propone una tematización de su experiencia del exilio a través del estudio de sus obras teatrales Medea, la encantadora y La sangre de Antígona, las cuales presentan a personajes marcados con el estigma de la liminaridad. Este teatro, en tanto que escritura de una cierta experiencia límite del exilio, no puede ser leído sin sacudir las categorías políticas y estéticas que comúnmente manejan hoy los historiadores que se han ocupado de su obra.
\end{abstract}

Palabras clave: José Bergamín, teatro, exilio, historia, literatura española.

The eccentric position of José Bergamin in the history of Spanish literature can be explained by the fact that his oeuvre is difficult to read, and also hard to integrate into the history that shapes it. This article intends to thematize Bergamin's exile experience by studying his plays Medea, la encantadora, and La sangre de Antígona, all of which feature characters marked by the stigma of liminality. As representations of the written expression of a borderline experience during exile, these plays cannot be addressed without challenging the current political and aesthetic categories commonly used by historians who have explored Bergamin's work so far.

KEY WORDS: José Bergamín, theatre, exile, history, Spanish literature.

Este trabajo forma parte del proyecto de investigación Escena y literatura dramática en el exilio republicano de 1939: final [FFI2010-21031/FILO], del que formo parte. 
Si el arte es percibido de una manera estrictamente estética, no es percibido de una manera estéticamente correcta. Sólo donde también se siente lo otro del arte como una de las primeras capas de la experiencia del arte, se puede sublimar al arte, disolver la implicación material sin que el ser-para-sí del arte se vuelva indiferente. El arte es para sí y no lo es; pierde su autonomía sin lo heterogéneo a él [...]. El

arte es a su otro como un imán a un campo de limaduras de hierro.

(Theodor W. Adorno, Teoría estética, pp. 16-17)

José Bergamín continúa siendo hoy a grandes rasgos, en el panorama de las letras castellanas, un fantasma, estatuto que el autor empezó a reivindicar para sí mismo a partir de su segundo exilio a mediados de los años sesenta. Ese carácter fantasmal - palpable en el espacio liminar que ocupa en las historias de la literatura- se concreta en la dificultad de leer su obra; y esa dificultad no es interna ni externa, sino fruto de la conjunción de una propuesta de escritura con una situación histórica determinada, que es la nuestra. Los problemas de lectura de Bergamín incluyen diferentes niveles: desde la dificultad de tener sus escritos a mano hasta la dificultad de interpretarlos una vez que esa labor ya ha sido parcialmente cubierta, pasando por la censura, lo problemático de la datación de algunos de sus textos e, incluso, la imposibilidad de establecer de una vez por todas la "identidad bibliográfica de cada una de sus obras" (Agamben, "Identificación..." 84).

Dado que la Historia de la Literatura Española sigue cumpliendo una función, si no única, sí fundamental en la canonización de escritores nacionales, un escritor tendrá serios problemas en ser canonizado si no logra integrarse en esa historia ${ }^{1}$ que, no lo olvidemos, es una historia de la nación. El canon (lo digno de ser leído), la tradición (la conexión de la obra con un discurso legitimador y unas prácticas que permiten reconocerlo) y, finalmente, la nación (espacio político-jurídico que da territorialidad, en el espacio y en el tiempo, a los dos problemas anteriores) quedan así agavillados en un único problema. Ese canon, sometido siempre a crítica y revisión en las sociedades que tienen un campo cultural relativamente autónomo, es la última abstracción de toda una serie de procesos sociales en los que participan los agentes productores

En este sentido, José-Carlos Mainer afirma: "La historia de la literatura es -o habría de ser- la historia de la historia de la literatura" (Mainer 275). 
de la cultura. Sin temer ser demasiado expeditivos, podemos decir que la canonización de un texto pasa por su edición (industria editorial), por su tratamiento historiográfico (propio de la academia) y, finalmente, por el trabajo de la crítica (promovido básicamente a través de la academia y del periodismo).

Sin el trabajo editorial y el de los comentaristas, no sería posible la constitución de un clásico ni de una obra canónica. En esas lecturas críticas la literatura se vuelve sobre sí y, tocando sus límites, se constituye como tal. La literatura moderna es, precisamente, la aventura a través de la cual la literatura se busca a sí misma sin jamás encontrarse, abriendo el movimiento que le es propio. Ahora bien, ¿qué ocurre cuando una obra queda desgajada de ese bloque (que, no hay que olvidarlo, es un bloque histórico)? ¿Qué ocurre cuando una obra es arrojada por la borda o queda a la deriva, separada del espacio natal, del espacio nativo de la nación?

Se diría que, en sus múltiples concreciones, el exilio español de la guerra civil es un lugar privilegiado para preguntarse por esta cuestión. Mari Paz Balibrea, en un libro en el que estudia el lugar que ocupa y los usos a los que se somete la literatura del exilio en el presente, sostiene que "el exilio implica un movimiento centrífugo [...], un punto de fuga del mapa nacional", por lo que, "como exceso de la nación que inició la expulsión, el exilio enfrenta a la perspectiva de cualquier disciplina enmarcada por fronteras nacionales con una aporía" (Balibrea 84). Ello -en un contexto en el que el exilio se ha vuelto una realidad irrecusable-hace necesario repensar las categorías políticas con las que, mecánicamente, seguimos tratando de entender una realidad que acaso ya no se adecúa a nuestros discursos. Giorgio Agamben -quien se ha interesado por la obra de Bergamín, al que consideraba su maestro- ${ }^{2}$ es, en ese sentido, uno de quienes más ha hecho por repensar las categorías políticas de nuestro presente a la luz de la experiencia política del siglo XX. En Homo sacer. El poder soberano y la nuda vida se lee:

Hay que considerar al refugiado como lo que en verdad es, es decir, nada menos que un concepto límite que pone en crisis radical las categorías fundamentales del Estado-nación, desde el nexo nacimiento-

\footnotetext{
"Asked about his intellectual masters in an interview from 1985, Agamben spoke of both Heidegger and José Bergamín, noting that during their lifetimes he thought of them as "examples and as friends" and that "only after their deeaths did I come to think of them as masters [maestri]" (De la Durantaye 395).
} 
nación al nexo hombre-ciudadano, y permite así despejar el terreno para una renovación categorial que ya no admite dilación alguna, con vistas a una política en que la nuda vida deje de estar separada y exceptuada en el seno del orden estatal (170).

Y, ¿no cabría plantear una problemática análoga respecto a una institución literaria que tan íntimos vínculos ha tramado, desde su surgimiento en el siglo XVIII, con el Estado-nación?

\section{EL TEATRO POPULAR DE BERGAMÍN}

La obra literaria de Bergamín se deja interrogar legítimamente -y, creemos, con resultados productivos-a partir de esa problemática. Ahora bien, el teatro no es inmediatamente literatura. Y, en ese sentido, supone un problema si cabe mayor dentro de su obra. El contacto con el público, que en la literatura moderna puede quedar diferido, se vuelve irrecusable en el teatro, dado que éste nace para ser interpretado; y un teatro que no se interpreta es un teatro huérfano de público.

Bergamín compartía estos presupuestos. Para él, el teatro era un arte popular: "Teatralizar es popularizar, siempre. Y a la inversa: todo lo que se populariza es porque se teatraliza de algún modo. El teatro es un instrumento, una máquina de popularizar" (Bergamín, Mangas 25). Ya desde sus primeros textos de teoría teatral de los años veinte, Bergamín dejará establecida esa idea, que ya nunca abandonará ${ }^{3}$. En un escrito de 1924, en el que trata de conciliar la deshumanización del arte de Ortega y Gasset con su propia reivindicación popular, afirma tajantemente -en lo que constituye una crítica directa a Pirandello- que el teatro no puede ser antipopular (Bergamín, "Criba" 42). La ligazón entre poesía, teatro y pueblo es crucial en su pensamiento teatral. Órgano de exteriorización espiritual, el teatro es voz y representación figurativa del pueblo que se reúne en torno a él. Pueblo y teatro se llaman y reclaman mutuamente: "Un pueblo se conoce cuando se verifica definiéndose por el teatro: cuando se teatraliza. Un teatro se verifica cuando se define conociéndose por su popularidad: cuando se populariza" (Bergamín, Mangas

3 Para la idea del teatro de José Bergamín pueden consultarse Santa María, El teatro... y su artículo "Tablas y diablas...". 
25). El teatro, en Bergamín, cumple una función cognoscitiva y existencial. A través de la poesía, hace ver y saber la propia condición humana. "El espejismo teatral", escribe, "es la imagen viva de nuestros actos porque los aprisiona enigmáticamente en una máscara de temporalidad: porque nos los muestra encendidos e iluminados por ella, transparentándolos imaginativamente por el pensamiento como si estuviéramos soñando; porque nos los hace ver, de ese modo, en un breve espacio poético" (Mangas 51). En "Musaraña del teatro. Poesía a voz en grito. Tablas y diablas no son más que imaginación", texto de 1943, Bergamín presenta el teatro como una realidad eminentemente imaginativa, en la que -"entre tablas y diablas"- se "enjaula" al pensamiento (El pasajero 271). El espacio escénico otorga "una caja de resonancia imaginativa para el pensamiento, por la palabra" (282). A través de ella, "todo en el teatro es poesía y por y para la poesía" (274); y la poesía que se realiza en el teatro aparece, a su vez, como "la realización y verificación escénica de la conciencia humana" (275). Por eso mismo puede Bergamín ligar teatro y teología a través de una conciencia que es autoconciencia ${ }^{4}$, pues "teatro y religión coinciden, natural y sobrenaturalmente, en hacerse, por la poesía, expresión, y comunicación, o comunión, de la conciencia humana" (282). El teatro, así presentado, sería un instrumento de autoconciencia que se da a sí mismo un pueblo para sostenerse poéticamente a través de figuraciones por las cuales es posible trascender el momento presente elevándolo a una dimensión más esencial (Beltenebros 18).

Lo problemático del planteamiento de Bergamín salta a la vista. ¿Puede haber, podría haber un teatro popular en el siglo XX? Desde el momento en el que la consistencia específica de la comunidad se ha vuelto problemática, ¿cómo va a haber un teatro que la exprese? Las declaraciones del autor sobre su propia producción dramática son, sin duda, sintomáticas. La inadecuación de su producción teatral respecto a sus ideas teatrales apunta una dificultad. ¿No sería posible realizar un gran teatro, análogo a la tragedia griega y al drama barroco, en el siglo XX? Y, de ser así, ¿se debería a la incompetencia

\footnotetext{
Escribe en "La pura verdad por el arte de vestir al muñeco": "El teatro, se ha dicho, es una reflexión del hombre sobre sí mismo. En el teatro el pueblo reflexiona sobre sí mismo como un hombre. En este sentido, esencialmente humano, era popular el teatro griego y lo fue el español católico del XVII" (p. 46). Y en "Musaraña del teatro. Poesía a voz en grito. Tablas y diablas no son más que imaginación": "Todas estas cosas de teatro, por serlo, lo son de poesía. Y la realidad humana que nos ofrecen, es, por eso mismo, el espejo en que se refleja nuestra conciencia" (El pasajero 280).
} 
de los dramaturgos? ¿O quizás podríamos reconocer otra razón de más peso? El teatro de Bergamín ha aparecido durante mucho tiempo, en palabras de Ma Teresa Santa María Fernández, como un “"intento" de algo que pudo ser pero que se frustró" (El teatro 11). Por lo demás, la propia actitud del autor respecto a su obra teatral ha venido a reforzar este juicio. Así, afirmaba en 1983, refiriéndose al conjunto de su obra teatral: "Mi intento no llega a ser teatro, y se queda, a mi juicio, en teatro para leer, en teatro para la butaca de casa" (Cit. en Santa María, El teatro 256).

¿Hasta qué punto se trata de un teatro frustrado, de un teatro literario o de un teatro para leer? Si la vocación del teatro es, como hemos visto, eminentemente escénica, un teatro literario, ¿no sería un teatro frustrado? Sin duda. Ahora bien, el problema al que se enfrenta Bergamín es aun más grave. Pues desde 1939, momento en el que el autor es rechazado fuera del espacio nacional, su teatro ha tenido problemas no solo para ser teatro, sino también para ser literatura 5 .

El esfuerzo, mencionado más arriba, de Agamben por repensar en profundidad las categorías políticas de la actualidad a la luz de la historia del siglo XX se muestra sumamente productivo a la hora de interpretar la escritura de un autor como Bergamín. Pues, desde su expulsión del espacio nacional, puede comprobarse cómo la situación política del escritor se comunica, por fuerza, a su escritura. La posición de enunciación del escritor -su relación con los discursos contemporáneos-, hasta entonces firme y claramente definida, se va a ir viendo tocada de irrealidad a partir de 1939. La España republicana, fuertemente articulada a través del conjunto de prácticas y de mecanismos que constituyen la existencia de un Estado ${ }^{6}$, se convertirá en una España peregrina que, al poco tiempo -y descubriendo la ausencia de suelo nacional en el que volver a anclar sus raíces en un territorio-, se tornará espectro de sí misma: realidad fantasmal en la que se mezclan los tiempos y pierden consistencia las categorías.

\footnotetext{
Este problema ha sido tratado en Hidalgo Nácher, "El teatro de José Bergamín", Don Galán.

6 Para entender el funcionamiento práctico de un Estado - en contraposición a la teoría clásica del Estado, que hace de él un lugar neutro, y de la teoría marxista, en tanto tiende a reducirlo a su función social- son fundamentales algunas de las enseñanzas de Bourdieu en el Collège de France, donde el autor propone "substituer à l'État les actes qu'on peut appeler les actes d" "État"-en mettant "État" entre guillemets-, c'est-à-dire des actes politiques ayant des prétentions à avoir des effets dans le monde social" (Sur l'État 26).
} 
Ese giro puede observarse en algunos personajes del teatro bergaminiano. Pues si La hija de Dios y La niña guerrillera (escritas y publicadas en México entre 1944 y 1945) todavía continúan la vía épica del teatro de la guerra, Melusina y el espejo (1949) supone un giro en su teatro. Tras esas dos obras, en las que el compromiso político era fundamental, esta otra supone una vuelta a problemáticas abordadas antes de la guerra civil. Con ella, y tras otras dos que -herederas del trabajo teatral comenzado durante la guerra- bien pueden calificarse de "teatro de circunstancias", Bergamín traza una figuración del amor a través de un personaje femenino que, más que una mujer, es el paradigma de la feminidad. Obras posteriores, como Medea, la encantadora (publicada en Uruguay en 1954) y La sangre de Antígona (publicada en 1983, pero escrita presumiblemente en los años de su primer exilio francés, entre 1954 y 1958 (Santa María, El teatro 31), y cuyo desfase cronológico es ya significativo respecto a su vocación y estatuto "teatrales"), mostrarán a personajes marcados, de uno u otro modo, con el estigma de la liminaridad. En efecto, ni Antígona como transgresora de la ley ni Medea en tanto que extranjera pertenecen de pleno derecho al reino de los vivos. La lectura que se propone a continuación tratará de reconstruir la problemática hacia la que apunta la consistencia específica de esos personajes bergaminianos.

De ese modo, y como trataremos de mostrar en lo que sigue, el teatro de Bergamín no puede ser leído sin sacudir las categorías políticas y estéticas que aplicamos comúnmente a los textos. Dado que es un teatro fronterizo, abierto a "rutas infernales" (Bergamín, "Acotaciones a Medea", Medea, 319) -en los límites del espacio nacional, en los límites del teatro y en los límites de la literatura-, por fuerza tiene que interpelar a nuestro discurso, desestabilizándolo. De ese modo, al acercarnos a una "obra" como ésta, nunca podemos saber si lo que la hace extraña son sus propios límites o los nuestros.

\section{ANTÍGONA O EL FANTASMA}

En la Antígona de Bergamín el conflicto entre ella y Creón, entre la ley divina y la ley humana, entre la heroína trágica y el tirano, aparece minimizado. En su lugar, la obra se centra en Antígona y en su propósito de no separar en la muerte a aquellos que estuvieron separados en vida. "Murieron matándose", dice el Mensajero refiriéndose a Etiocles y a Polinice: "Uno a manos del otro, en un solo abrazo de muerte. Su sangre se ha juntado en la tierra, pero sus cuerpos yacen separados para siempre por la voluntad de los vivos". 
Contra esa voluntad que "rinde su homenaje a Etiocles dándole las honras fúnebres del sepulcro, mientras deja a Polinice insepulto" (La sangre 6) se levanta Antígona.

La reescritura de la tragedia de Antígona llevada a cabo por Bergamín es, de ese modo, extremadamente significativa. Tanto más cuanto dicho personaje ha sido ampliamente tratado en el teatro español del siglo XX (Bosch 84). La posición de enunciación del personaje reproduce el conflicto en el que el propio autor, en tanto que sujeto político, se ve preso. Frente a otras versiones del mito, la singularidad de la reescritura bergaminiana radica en gran medida en el mandato de las sombras de Polinice y Etiocles, quienes claman su propia ley, repitiéndole una y otra vez a Antígona lo siguiente:

SOMBRA DE POLINICE. ¿Por qué vienes a sepultarme?

SOMBRA DE ETIOCLES. ¿Por qué no vienes a sacarme del sepulcro? (La sangre 14).

Las sombras se rebelan, de ese modo, frente al rito fúnebre. Negándose a ser enterradas oficialmente -lo que haría caer la muerte de los dos hermanos del lado de la ley y la tradición, reabsorbiéndola en la comunidad del duelo-, pretenden ser libertadas de la muerte.

SOMBRA DE POLINICE. Antígona, ¿por qué vienes a ocultarme? SOMBRA DE ETIOCLES. ¿Por qué no vienes a libertarme del sepulcro? (La sangre 16).

Los muertos hablan y, al hablar, piden que se les retiren los ritos funerarios. Esa variación bergaminiana de la tragedia de Sófocles indica una posición de enunciación sumamente peculiar, y que sin duda cabe ligar a las transformaciones políticas acaecidas desde comienzos del siglo XX. Como afirma Agamben, "la creciente desconexión entre el nacimiento (nuda vida) y el Estado-nación es el hecho nuevo de la política de nuestro tiempo" (Homo sacer 223). En el siglo XX se ha asistido a la desintegración de la polis, y el Estado de Derecho, que aseguraba la ciudadanía a través del principio de natalidad propio de la nación, ha mostrado sus límites. El exiliado aparece así como una figura límite en la que entran en crisis los presupuestos básicos de un Estado-nación que cumplía la función de articular un ordenamiento legal con un territorio. Escribe Agamben: 
Si los refugiados (cuyo número no ha dejado de crecer en ningún momento en nuestro siglo, hasta llegar a incluir hoy a una parte no desdeñable de la humanidad) representan, en el orden del Estadonación moderno, un elemento tan inquietante, es, sobre todo, porque, al romper la continuidad entre hombre y ciudadano, entre nacimiento y nacionalidad, ponen en crisis la ficción originaria de la soberanía moderna. Al manifestar a plena luz la separación entre nacimiento y nación, el refugiado hace comparecer por un momento en la escena política la nuda vida que constituye el presupuesto secreto de ella (Homo sacer 116-117).

A la luz de estas reflexiones, puede entenderse que lo que está en juego en el gesto de las sombras de los dos hermanos muertos es, precisamente, la reivindicación de una muerte desnuda, una muerte que ya invocaba para sí Antonio Machado en su retrato de 1906 ("Y cuando llegue el día del último viaje, / y esté al partir la nave que nunca ha de tornar, / me encontraréis a bordo ligero de equipaje, / casi desnudo, como los hijos de la mar") y que llegó a cumplirse un 22 de febrero de 1939 en Collioure, fuera del territorio nacional. Agamben reconoce en esta figura la condición de posibilidad-hecha necesaria por la historia- de una nueva política.

Todo ello permite entender la Antígona de Bergamín en su propia especificidad histórico-política. En ella está en juego el vínculo que el escritor exiliado establece con su propia condición. La relación de Bergamín con su propia muerte civil no deja de evocar, en ese sentido, la actitud de las sombras de los hermanos muertos. El autor se refirió varias veces en sus poemas a su propio entierro ("Amigos míos, os pido / que escuchéis mi último ruego: / el día que yo me muera / no vayáis a mi entierro" [Poesías 111]), y su actitud fue siempre la de una indiferencia activa. El siguiente poema -muy posterior en el tiempo- es sumamente elocuente:

Si no he tenido en mi vida

en dónde caerme muerto ¿para qué voy a querer después de morir tenerlo?

No quiero nicho, ni tumba, ni caja, ni pudrideros.

Si hay una fosa común echad en ella mi cuerpo: 


\author{
o, si no, al mar; o dejadlo \\ en el campo, sobre el suelo, \\ para que lo queme el sol \\ o se lo coman los cuervos (Poesías 819).
}

En sus últimos años de vida, con más de ochenta años de edad, Bergamín se permitía hablar así de su propia muerte; y lo hacía en nombre de su calidad de exiliado. Es, precisamente, el no haber tenido sitio "en dónde caerse muerto" lo que le llevará a renegar de la sepultura. La muerte de Polinice es, en ese sentido, más digna para Bergamín que la de Etiocles, falseada por todas las pompas oficiales. La irreligiosidad de esos versos -su impiedad-es la misma que alienta la crítica a la piedad de Antígona o de Medea. Esos dos personajes comparten una misma situación límite ("Mi alma está muerta", dice Antígona, "y habla el lenguaje de los muertos"). Antígona queda fuera de la ley, partida literalmente por la muerte mutua de sus hermanos que prolonga la maldición paterna. "Yo cubriré de tierra y de ceniza el abandono del cuerpo sin vida" ( $L a$ sangre 10 [el destacado es mío]), había dicho Antígona. A lo que su hermana Ismena le había respondido: "No lo toques, Antígona. Teme la maldición de los vivos" (10). Al acercarse al cadáver insepulto -él mismo convertido en tabú- su sacralidad le es contagiada por contacto ${ }^{7}$. Tal es el motivo por el cual, cuando los soldados se acerquen a detenerla, no se atreverán a tocarla:

ANTÍGONA. ¿Por qué no me prendéis?

SOLDADO I. Porque no nos atrevemos a tocar tu cuerpo (La sangre 22).

Su concepto de la piedad es, así, diametralmente opuesto al de sus contemporáneos. "Me espanta la piedad" (10), dice Antígona al principio de la obra. Y algo después, en su diálogo con Ismena, mujer piadosa donde las haya:

ANTÍGONA. Tú no puedes seguirme. Porque tú no lloras por ellos: lloras por ti. Y por mí. Lloras por nosotros. Tienes miedo. Y a mí no

\footnotetext{
Freud ha expuesto en Tótem y tabú el modo de funcionamiento específico del tabú, el cual se transmite por contagio: "La expresión tabú [...] hace resaltar un carácter que permanece común a lo sagrado y a lo impuro a través de todos los tiempos: el temor a su contacto [...]. La creencia, inherente al tabú primitivo, en un poder demoníaco oculto en determinados objetos y que castiga el uso de los mismos o simplemente el contacto con ellos, embrujando al culpable, no es, en efecto, sino el temor objetivado" (524).
} 
me basta con este espanto.

ISMENA. ¿Es eso piedad?

ANTÍGONA. ¡Porque es amor!

ISMENA. ¡Terrible amor! ¡Espantosa piedad!

ANTÍGONA. ¡Dejadme a mí sola la piedad del amor! Llevaros vuestro miedo (12).

Las dos maneras de piedad, las dos actitudes de las hermanas ante la muerte de los hermanos, se dejan resumir en el primer parlamento del Mensajero:

La sangre de los dos hermanos se hace llanto en el corazón de la tierna Ismena, y se levanta como una llama ardiente en el alma luminosa de Antígona, que eleva hasta los cielos su grito, como una interrogación acusadora, entre los vivos y los muertos (6).

Al llanto de Ismena, agua él mismo, se opone la llama de Antígona, sangre y fuego, la cual clama a los cielos, acusadoramente, en un lenguaje espectral. Pues desde el momento en que Antígona se deje arrastrar por esa pasión y entre en contacto con lo sagrado se convertirá en un fantasma ("SOLDADO I. ¿Quién es esa mujer que anda entre los muertos? SOLDADO II. Parece un fantasma de Antígona" [18]), viéndose condenada a transitar entre la vida y la muerte sin poder habitar ninguno de esos dos espacios.

Esta figuración bergaminiana, que nos presenta -frente a la versión de María Zambrano- una Antígona que no puede ni vivir ni morir, y que no halla la resolución de esa condena, se encuentra íntimamente ligada a la experiencia de disolución propia del exilio y a la particular posición de enunciación de Bergamín en la España franquista y -posteriormente- democrática.

\section{LA CÓLERA MONSTRUOSA DE MEDEA}

Medea, por su parte, se encuentra en un espacio de incertidumbre parecido. Ella es una semi-diosa exiliada (cuyo "origen bárbaro, expresamente subrayado por el griego en contraste con el ambiente que la rodea"8 señala Bergamín) y

$8 \quad J o s e ́$ Bergamín, "Prólogo" a Medea, la encantadora, en Ma Teresa Santa María Fernández ("El teatro del exilio de José Bergamín" 288). El resto de citas de Medea, la encantadora remiten a la edición presentada en dicho trabajo. 
no participa de la mortalidad sino a través de sus hijos y de su amor a Jasón ("JASÓN. (Riendo.) ¡Divina Medea! MEDEA. Sólo para ti no quise serlo: sólo por tu amor quise ser humana" [Medea 302]). Como indica Bergamín, "mi Medea no es humana, no tiene pasiones, no es una mujer. Es una diosa. El amor de Medea es un amor divino, que no aparece en las Medeas clásicas. El amor de Medea es un amor divino que no tiene nada que ver con el sexo, con la generación mortal. Y por eso mata a los hijos, porque niega su propia maternidad, porque ella es divina, inmortal" (cit. en Santa María, Tesis 302).

Medea es una hechicera bárbara que ve cómo su hombre va a casarse ese mismo día con otra mujer. Ese va a ser el motivo de la explosión y de la ruptura. Situada doblemente en tierra de nadie (fuera de su país y abandonada por su marido"), ya nos dice en su primer parlamento que habita "en el destierro mudo de mi vida" (Medea 295). El desterrado es alguien que, por la propia condición a la que está expuesto, se ve obligado a reconocer el cambio. Así se muestra en uno de los primeros parlamentos de la obra: "AMA. ¿Por qué dudas ahora de ti misma, Medea? MEDEA. Porque he empezado a ver con mis ojos el tiempo" (296). Esa visión del tiempo - de la nadería de las propias convicciones- llevará a Medea a experimentar en sus propias carnes la inversión por la cual, al desinvestirse el mundo, lo que era queda identificado con nada: "AMA. Cuando miras, tus ojos parece que se asombran / como si en la luz vieran un oscuro silencio" (294). En ese trance se produce el descubrimiento de las profundidades del alma cuando el corazón siente romperse las vías que, ligándolo a la realidad, lo conectaban a su sueño. Así, le dirá el Ama: "En tus labios se enciende la noche de tu sangre / cuando apaga tus ojos la aurora de tu sueño" (295). Esa "noche de la sangre" a la que se refiere el Ama es la que justifica el subtítulo de la obra ("Explosión trágica en un acto") y aparecerá en la obra como una llama que todo lo consume. Por esos labios hablaría, según María Zambrano, "esa víscera secreta y delatora" llamada "corazón" (Hacia un saber 62), que adopta formas violentas cuando no logra ser escuchada. Esa dimensión destructora del corazón, ligada a lo que la escritora llama el "rencor" ${ }^{10}$, aparece presentada por Bergamín -a través de lo que constituirá,

$9 \quad$ Un cantaor nos presenta la doble imposibilidad de arraigar que la constituye: "En cuerpo y alma eres aire: / el alma, cielo de todos; / el cuerpo, tierra de nadie" (Medea 298).

10 "El rencor se asienta en la zona misma en que la vida necesita de esa transparencia que sólo proporciona la verdad. Como no puede prescindir de ella, parte en su busca; mas al no estar preparada para recibirla, surge adueñándose el rencor" (Zambrano, La confesión 22). 
desde el momento en el que se haya llevado a cabo la transformación, una inversión sistemática de los valores- precisamente como piedad:

CREUSA. ¿Pues no es venganza lo que te mueve a revelarme tan terribles secretos?

MEDEA. No, sino piedad. La piedad que tú me pedías.

CREUSA. ¡Qué espantosa piedad!

MEDEA. Di mejor, Creusa, ¡qué piadoso espanto! (Medea 307).

Medea matará a sus hijos y, tras hacerlo, le espetará a Jasón y al Ama:

MEDEA: ¡No podéis mirarlos! ¡No podéis mirarme sin terror! Ésta es mi piedad: con el mismo amor que les di la vida se la he quitado: ¡con el mismo amor (314).

Tal es la clave de bóveda de la obra: el que da la vida y la arrebata es "el mismo amor". Medea muestra, a través de ello, la raíz terrible del amor. Y lo que descubre, a través de ello, es la estirpe criminal de Jasón:

Yo enmascaré con mi alma, por amor, los crímenes que Jasón cometía por este amor mío [...]. Yo puse mis manos de sueño entre las suyas para empapar con ellas, con mi alma, la sangre de los hombres que morían por culpa nuestra, por culpa de nuestro único y divino amor. Yo tomé sus crímenes en mis manos para que no lo fuesen. Sólo el amor podía hacer por mis manos ese prodigio (305).

El amor, como un velo, enmascaraba de luz la sangre; pero, cifrada la ruptura, "mis palabras", dice Medea, "destejen la trama ilusoria de mi vida para mostrarte la verdad del amor que tú tanto temes" (305). Solo en este punto los "encantos" y "encantamientos" de Medea adquieren todas sus dimensiones. "Quiero enseñarte a ti", le dirá a Creusa, "lo que nadie pudo ver jamás de Medea: su desencanto" (306). Es precisamente ese desencanto el que va a tener que tejerse, enmascararse, en la obra, la cual ha de mostrar -tal como escribiría en un poema el propio Bergamín- "la irrealidad de lo vivido"" Así, dirá Medea a Creusa: "Con este hilo puro de mi alma que deshace el tejido ilusorio del pasado, fue entretejido el sueño de mi vida. Quiero con

11 “ ¡Ay!, todo lo que ha sido / la realidad del sueño / será la irrealidad de lo vivido: / será su desensueño / al despertar de un sueño interrumpido" (Bergamín, Poesías 698). 
este invisible hilo tejerte un maravilloso traje de encanto, una túnica de fuego y de sangre: ¡un vestido de novia inmortal!” (Medea 310-311). Vestido con el que Creusa morirá, abrasada por las llamas.

De ese modo, frente a Antígona, quien es abandonada por la ley, Medea -en el filo del abandono- desafía la ley desde la ley misma, resolviendo en sí misma los contrarios. Por ello Jasón le grita: “¡Monstruo!” (315). Un monstruo es, en efecto, un ser que reúne en sí mismo elementos heterogéneos que atentan contra la naturaleza. Y Medea, en su persona, aúna lo maravilloso y lo terrible del amor: su encanto y su desencanto. Medea se constituye en esa figura, que así se muestra ante nuestros ojos: “¡Atrévete a verme, tú, cobarde Jasón, tal como soy, frente a las estrellas tenebrosas, que, solas, no tiemblan de mirarme!... ¡Sólo las estrellas me miran!... ¡Mira tú, tus hijos de sangre, enterrados en ella!..." (315).

\section{EN LAS FRONTERAS DEL ABANDONO}

Como un fantasma entre los vivos.

Como una sombra entre los muertos (La sangre 24).

Antígona ha sido rechazada, al mismo tiempo, de la vida y de la muerte. En el sentido técnico que expone Agamben, ha sido abandonada ${ }^{12}$. Ese abandono a partir del cual Agamben define la condición del homo sacer, sitúa al sujeto más allá del derecho humano y del divino. Concebido en este preciso sentido, lo sagrado no va ligado a ningún culto ni a ningún ritual sino que, al contrario, es aquello que - al ser puesto en bando por el poder- no puede ser sacrificado. Antígona, al ponerse en contacto con el cuerpo sagrado de su hermano exiliado, se hace ella misma sagrada y, desde ese momento, quedará presa en una estructura de doble negación que, según la fórmula de Agamben, la convierte en un cuerpo "insacrificable al que, sin embargo, se puede matar" (Homo sacer 129). Rechazada de ambos ámbitos, exclama: "Si

12 "Lo que ha sido puesto en bando es entregado a la propia separación y, al mismo tiempo, consignado a la merced de quien lo abandona, excluido e incluido, apartado y apresado a la vez" (Agamben, Homo sacer 142). 
los muertos no quieren mi vida, ¿por qué quieren los vivos mi muerte?” ( $L a$ sangre 18). Acaso ése sea uno de los motivos por los que se acabará dando la muerte ella misma, para cumplir ese mandato irrealizable que le atenaza más fuerte cuanto más firmemente la abandona:

SOLDADO I. ¿Por qué buscas la vida entre los muertos?

ANTÍGONA. Porque no amo la vida.

SOLDADO II. ¿Y amas la muerte?

ANTÍGONA. (Pensativa) Tampoco la amo (20).

Esa estructura de doble negación que neutraliza el paradigma (ni $x$, ni $y$ ) es la que define la posición de la Antígona bergaminiana. Y, acaso por ello mismo, se verá obligada a seguir el mismo destino que su hermano. "¿Cuál puede ser mi esposo", dice, "sino mi propio cuerpo puro, convertido en vacío esqueleto, despojo de la muerte?". A lo que replican los coros:
¡Mirad, mirad a Antígona!
Como un fantasma
entre los vivos.
Como una sombra
entre los muertos.
No es como nosotros
ni como ellos.
No la quiere el Infierno.
Y la rechaza el Cielo.
¡Mirad, mirad a Antígona! (24).

Situada entre dos reinos, no rige sobre ella ni la ley divina ni la ley humana: "Parece un fantasma entre los vivos / y es una sombra entre los muertos". La condena de Antígona, que la convierte en persona sagrada, es de un orden especial: no se le va a aplicar el Derecho, sino que -de forma mucho más inquietante- se le va a desaplicar. Los coros registran esta "condena" de manera precisa: "Tu sangre no será vertida. / Y tu vida será sacrificada" $(26)^{13}$.

13 Agamben transmite unas palabras de Sobre la significación de las palabras, de Festo, en las cuales se define la figura jurídica del homo sacer, perteneciente al derecho romano arcaico: "Hombre sagrado es [...] aquél a quien el pueblo ha juzgado por un delito; no es lícito sacrificarle, pero quien le mate no será condenado por homicidio" (Homo sacer 94). Agamben, que toma esa figura para problematizar el pensamiento político del siglo XX, 
Las intervenciones que vienen a continuación se vuelven, a esta luz, sumamente inquietantes. El Coro repite una y otra vez: "Nadie la juzgue. / Nadie, nadie. / Nadie la condene. / Nadie, nadie”, “ „Nadie la juzgue! / ¡Nadie la condene!” (28-29). ¿Cómo leer o escuchar estas frases? Si en vez de tomarlas como enunciados morales les restituyéramos su carácter jurídico, nos hallaríamos, no ya ante el deseo de salvar a Antígona de la ley, sino ante la condena que hace que la ley no pueda caer sobre ella. Pues lo que descubre el abandonado es que la manera más terrible que tiene la ley de caer sobre él es desaplicándose.

Se entiende, pues, que Creón no aparezca aquí como el tirano que era en la tragedia de Sófocles. Ahora ya no es necesario que el soberano emita un juicio: basta con que se abstenga de hacerlo. Todas las palabras de Creón serán, en ese sentido, un enunciado que aplica la ley retirándola: “CREÓN. ¡Basta! ¡Basta! / ¡Antígona! ¡Estás condenada a morir!” (36). “Estás condenada a morir", ¿es, verdaderamente, una fórmula a través de la cual el soberano condena a uno de sus súbditos a muerte, una fórmula a través de la cual el poder ejerce su derecho a dar muerte? ¿O más bien es un enunciado -que hubiera sido profundamente anacrónico en la Grecia de Sófocles- por el cual Creón constata una realidad y hasta, diríamos, se apiada de ella? Como es sabido, los actos de ley son performativos; ahora bien, el enunciado de Creón -que hemos de entender como un constatativo- no se deja entender performativamente. Pues, para serlo, tendría que utilizar una fórmula del

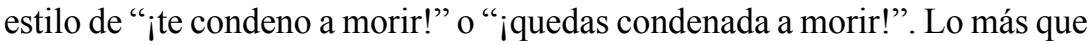
llegará a decir, en ese sentido, Creón, será: “iEs justo que Antígona muera!” (44). Y Antígona morirá.

Así dialogan en un momento de la obra Antígona y el Coro:

ANTÍGONA. ¿Cuál es el nombre del amor si no es vencimiento? CORIFEO $1^{\circ}$. El nuestro tiene un nombre sólo: queremos la vida. $\mathrm{Tu}$ amor no tiene nombre, Antígona; porque has traicionado la vida dándole el nombre de la muerte, abriéndole las puertas del infierno. CORO $1^{\circ}$. ¡Ay, vencido amor!

ANTÍGONA. Vosotros sois la voz del Infierno. Clamáis por una vida condenada. Yo grito por una invencible muerte. Por el vencido amor (10).

presenta la especificidad del homo sacer del siguiente modo: "la impunidad de darle muerte y la prohibición de su sacrificio" (96). 
En este diálogo está en juego la vida desnuda frente a las formas de vida. Negándose a aceptar una vida sin sentido, que ha quedado reducida a pura supervivencia, Antígona hace saber a sus acusadores que, si ella ha abierto las puertas del infierno, ha sido para darles voz a ellos: "Vosotros sois la voz del Infierno". Su muerte es el testimonio que señala el imperio de la muerte y la imposibilidad de habitar en el seno de la comunidad. Por ella, las categorías claras y distintas de la vida y la muerte quedan subvertidas y se descubre una vida que está constituida de raíz por su contrario: la muerte. Por eso, en un mundo en el que la vida no es verdadera vida, sino supervivencia, Antígona rechazará la filiación y se negará a traer hijos al mundo. "Yo no engendraré hijos de sangre" (16), dice la heroína. La verdadera vida es poética: vida con sentido, donde el sol es mi sol y los ciudadanos mis contemporáneos. Pero el espacio común ha quedado fracturado, y la paz de la ciudad semeja, a ojos de su exilio, la paz de las sepulturas (“CORO 1. ¡Ay de mí! ¡Ay de mí! Las desdichas son una afrenta para quien las mira. Y son las que vemos cuando tornamos del destierro" [8]). Ahí la ley queda identificada con el sepulcro; y los ciudadanos, con los muertos. El mundo político ha quedado desinvestido:

ANTÍGONA. No hay muerte, sino muertos.

SOLDADO I. Que nos impusieron la ley.

ANTÍGONA. Como sus murallas.

SOLDADO II. Y el pueblo debe defender la ley como sus murallas.

ANTÍGONA. ¡Las losas de la tumba! (20-22).

Antígona se suicida. Su muerte -que no tiene sentido-, queriendo ser un castigo, tendría que transmitirse como una maldición a la ciudad que la ha condenado. Dicha maldición es enunciada por Tiresias en forma de profecía ("TIRESIAS. Sobre vosotros caerán las sombras infernales de los muertos que con el vacío de sus ojos os abrirán las tinieblas para siempre" [42-44]). La violencia que Medea ejerce contra el mundo (contra su propia familia, que la ha abandonado, y contra sus hijos, que pertenecen a dicha familia), Antígona tolera que se aplique contra sí misma. De ese modo, si Medea encarna el furor poético, Antígona sostiene el testimonio. Lo que no se sabe es si hay oídos para escucharlo:

VOCES: ¿Por qué muere Antígona!

¿Por quién muere?

¿Para qué muere? 
Virgen como la luz y como la luz solitaria.

Pura como su voz, como la nube,

como el viento...

Y como el corazón vacío y tenebroso de la llama (58).

\section{BIBLIOGRAFÍA}

Adorno, Theodor W. Teoría estética. Madrid: Akal, 2004.

Agamben, Giorgio. "Identificación y desidentificación de un autor llamado José Bergamín". Archipiélago. Cuadernos de crítica de la cultura 46 (abril de 2001): 81-87.

Homo sacer. El poder soberano y la nuda vida. Valencia: Pre-textos, 2010.

Balibrea, Mari Paz. Tiempo de exilio. Una mirada crítica a la modernidad española desde el pensamiento republicano en el exilio. España: Montesinos, 2007.

Bergamín, José. Beltenebros y otros ensayos sobre Literatura Española. Barcelona: Noguer, 1973.

"La pura verdad por el arte de vestir al muñeco". Mangas y capirotes (España en su laberinto teatral del siglo XVII). Madrid: Ediciones del Centro, 1974.

"La sangre de Antígona". Primer Acto. 198 (marzo-abril de 1983): 48-69.

"Criba" (España. 404 [12 enero 1924]: 8-9). El pensamiento de un esqueleto. Antología periodística I. Málaga: Litoral, 1984.

Medea, la encantadora. En Santa María Fernández, Ma Teresa. "El teatro del exilio de José Bergamín”. Tesis Doctoral. Director: Manuel Aznar Soler. Universidad Autónoma de Barcelona, 2002. [Puede consultarse en: http://hdl.handle.net/10803/4880].

La sangre de Antígona (Misterio en tres actos). Il sangue di Antigone (Mistero in tre atti). Firenze : Alinea, 2003.

El pasajero III (otoño de 1943). El pasajero. Peregrino español en América (México, 1943-1944). A Coruña: Ediciós do Castro (Biblioteca del exilio), 2005.

Poesías completas I. Valencia: Pre-textos, 2009.

Bosch Mateu, Mireia. "El mito de Antígona en el teatro español exiliado". Acotaciones 24 (enero-junio 2010).

Bourdieu, Pierre. Sur l'État. Cours au Collège de France, 1989-1992. Paris: Seuil, 2012.

De la Durantaye, Leland. Giorgio Agamben: a critical introduction. Standford: Standford University Press, 2009.

Freud, Sigmund. Tótem y tabú (1913). Obras completas (vol. II). Madrid: Biblioteca Nueva, 1967.

Hegel, G.W.F. Filosofia del arte o Estética (verano de 1826). Edición de Annemarie GethmannSiefert y Bernadette Collenberg-Plotnikov (ed. bilingüe). Trad. Domingo Hernández Sánchez. Abada / UAM: Madrid, 2006.

Hidalgo Nácher, Max. "El teatro de José Bergamín”. Don Galán. Revista de investigación teatral $\left.\mathrm{n}^{\circ} 3,2013\right)$. 
Mainer, José-Carlos. "Sobre el canon de la literatura española del siglo XX”. El canon literario. Ed. Enric Sullà. Madrid: Arco/Libros, 1998.

Santa María Fernández, Ma Teresa. "El teatro del exilio de José Bergamín”. Tesis Doctoral. Director: Manuel Aznar Soler. Universidad Autónoma de Barcelona, 2002. [puede consultarse en: http://hdl.handle.net/10803/4880].

“Tablas y diablas en el teatro de José Bergamín”. Acotaciones 24 (enero-junio 2010): 119-146.

El teatro de José Bergamín. Madrid: Fundamentos, 2011.

Zambrano, María. La confesión: género literario. Madrid: Siruela, 2004.

"La metáfora del corazón”. Hacia un saber sobre el alma. Madrid: Alianza, 2008. 